\title{
Mercury distribution in Port Klang mangrove and estuarine sediment
}

\begin{abstract}
Mangrove and estuarine areas are important to the ecosystem and can act as a sink of pollutants, especially metal ions. However, the accumulation of metals in sediment can cause negative impacts on plant growth, microbial activity and soil fertility. The severity and nature of the impact is highly influenced by the type of metal found in the sediment. One of the metals that have adverse effects on the environment is mercury. Therefore, the objectives of this study are to determine the mercury concentration and its distribution in the study area. Sediment samples were collected from 30 sampling points that cover Langat River and Klang River estuaries, Lumut Straits, Pulau Klang and Pulau Indah in Selangor, Malaysia. The extractable mercury in sediment samples was determined at the laboratory using inductively coupled plasma mass spectrometry (ICP-MS). In this study, mercury was found to be concentrated along Lumut Strait especially in the mixing zone near the confluence of Langat River.
\end{abstract}

Keyword: Mercury; Mangrove sediment; Estuarine sediment; Mercury distribution 